\title{
Lutero y la astrología \\ Cristo Redentor como referente de humildad y liberación de la conciencia pecadora
}

\author{
Bettine Baader \\ Pontificia Universidad Católica de Valparaíso \\ bettine.baader@gmail.com
}

Resumen: El presente trabajo consta de una aproximación al pensamiento teológico de Martín Lutero a partir de su relación con la Astrología. Se ofrecerá un análisis del Prólogo que escribió en 1527 a la nueva edición de la Prognosticatio in latino (1488) del astrólogo alemán Johannes Lichtenberger (1438-1503), en compañía de algunos fragmentos de su obra teológica De Servo Arbitrio (1525). Una proyección analítica de aquellos conceptos más relevantes que derivan de su doctrina de la justificación por la fe, nos permitirá comprender la postura que el reformador alemán tuvo frente a la creencia astral de parte de sus contemporáneos. En esta ocasión intentaremos demostrar cómo el pesimismo con el cual se ha caracterizado la doctrina de Lutero referente al albedrío humano, pueda ser reemplazado por una apreciación consciente acerca de la preocupación que tuvo el monje por la ansiedad de los cristianos.

Palabras Claves: Cristo Legislador, Cristo Redentor, juicio divino, pecado, humildad.

Abstract: The present research focus its attention on Martin Luther's theological thought in relation to Astrology. Based on some passages of the De Servo Arbitrio, we offer an analysis about Luther's Preface (1527) on German astrologer Johannes Lichtenberger's Prognosticatio in latino (1488). Those central arguments which derive from his doctrine of justification through faith will lead us to his opinion about his contemporaries astrological thought. On this occasion we want to demonstrate how the pessimism that characterises Lutheran doctrine on human free will, could be replaced by a conscious appreciation on Luther interest on Christian anxiety.

Key Words: Christ the Legislator, Christ the Redeemer, divine judgment, sin, humility. 


\section{INTRODUCCIÓN.}

Uno de los motivos que impulsaron a Martín Lutero a verse envuelto en la disputa en torno a la disciplina de la Astrología, fue la relación que estableció la sociedad alemana entre él y la figura de un profeta revolucionario que había sido anunciada por uno de los astrólogos de corte del emperador Federico III (1440-1493), Johannes Lichtenberger (1438-1503). De acuerdo al historiador del arte Aby Warburg, el pronóstico que llegó a manos del reformador decía lo siguiente ${ }^{1}$ :

Este profeta tendrá un entendimiento certero y arte para muchas cosas y una gran sabiduría; sin embargo, a menudo mentirá hipócritamente y tendrá conciencia cauterizada [...] según la doctrina redentora de Cristo no se le debe seguir ${ }^{2}$.

Tanto enemigos como amigos del reformador -entre ellos, su discípulo Philipp Melanchton- repararon en esta gran coincidencia, surgiendo una serie de interpretaciones atingentes a los episodios político-religiosos del momento ${ }^{3}$. El mismo Lutero fue consciente de la relación entre su figura y la del profeta de Lichtenberger, de modo tal que en 1527 decidió publicar una nueva edición del pronóstico, precedido por un prólogo en el cual él mismo daba a entender los principios de la astrología y el trasfondo de su existencia, aprovechando la ocasión para contraatacar de un modo irónico y despectivo a todos aquellos quienes habían corroborado la correspondencia entre su persona y las constelaciones. Sucede, no obstante, que este documento ha pasado a ser uno más entre cientos de otros que

1 A. Warburg, "Profecía pagana en palabras e imágenes en la época de Lutero", en $E l$ Renacimiento del paganismo, Alianza, Madrid 2005, 446-511, 467.

2 Dieser Prophet wirdt ein treftlichen verstandt haben und vieler ding kunst und eine sehr grosse weissheit; doch wirdt er in heuchelen oft lügen reden un der wird ein gebrand gewissen haben [...] doch nach der heilsamen lehr Christi sol man ihm mit nicht anhangen. J. Lichtenberger, Die Weissagung Johannis Liechtenbergers deutsch, mit Schönen Figuren zugericht 1488, Frankfurt am Mein 1557, 33. Contamos también con la versión en castellano que se encuentra en la obra citada de A. WArbURG, Pronosticatio in latino, rata et prius non audita, Heinrich KNOblochtzer, Heidelberg 1488.

3 A.Warburg, "Profecía pagana..., 507. 
estuvieron empeñados en sacar a relucir los desaciertos de la disciplina y sus dificultades para convertirse en un arte certero ${ }^{4}$.

En la presente investigación proponemos volver a revisar el contra-argumento que se halla presente en el Prólogo (1527) de Lutero a la luz de su pensamiento teológico, teniendo como referente algunos fragmentos de su obra De Servo Arbitrio, escrita dos años antes del Prólogo, y en la cual esclareció una serie de conceptos derivados de su doctrina de la justificación por la fe, los cuales nos permitirán comprender la postura que el reformador tuvo frente a la creencia astral. Esto supone un procedimiento clave mediante el cual seamos capaces de advertir, cómo el pesimismo con el cual se ha caracterizado la doctrina de Lutero referente al albedrío humano, pueda ser reemplazado por una apreciación consciente acerca de la preocupación que tuvo el monje por la ansiedad de los cristianos. Como se verá, en lo que respecta al impacto sociocultural de las conjunciones astrológicas, descubriremos que la libertad humana adquirió dentro del pensamiento de Lutero un matiz particular que, junto a su idea sobre el pecado y la humildad, puede sugerir una nueva evaluación de su doctrina.

\section{LA FALSA CERTIDUMBRe DEL ALBEDRÍo hUMANO}

El argumento que desarrolló Lutero para referirse a la creencia que sus contemporáneos tenían en los prodigios celestes tiene absoluta relación con la interpretación unilateral que aquel hizo del Juicio Divino, según una lectura personal de las Sagradas Escrituras5. No obstante, su desdén hacia sus colegas contemporáneos habría surgido no solo de las divergencias de opinión atingentes a los asuntos doctrinales que venían sumándose al debate confesional, sino también de la percepción que ellos tenían de los Pronósticos Astrológicos, en especial, de una de las profecías que aparecía anunciada en la Prognosticatio in Latino (1488) del astrólogo

4 Siguiendo el famoso ejemplo de los gemelos que había dado San Agustín diez siglos antes, Lutero discutía que Esaú y Jacob habían sido hijos de un mismo padre y de una misma madre "nacidos en el mismo momento y bajo el mismo astro y, sin embargo, de naturaleza, condición y mentalidad enteramente opuestas", M. LuTERo, Colección de trabajos del doctor Martín Lutero, vol.62 (1543), 321. Traducido en A. WArburg, "Profecía Pagana..., 507.

5 De su recorrido teológico llevado a cabo en la Universidad de Wittenberg, destaca la vía cuádruple de interpretación, la lectio divina. Véase H. Graf, History of Biblical Interpretation. Renaissance, Reformation and Humanism, Society of Biblical Literature, Atlanta 2010. 
alemán, Johannes Lichtenberger. A partir de lo anterior, se hace necesario un estudio acerca de la relación entre su propuesta teológica de la sola fe y su rechazo hacia la representación social de los prodigios celestes que existía en aquel entonces. Porque más allá de los argumentos mediante los cuales Lutero se sumó a la tendencia de la época por rechazar los métodos de interpretación del arte astral (por ser considerados poco ortodoxos y de dudosa reputación), hemos reparado en algunos fragmentos del Prólogo que publicó el monje alemán en 1527 como respuesta a la predicción de 1488 , y en los cuales se ha podido evidenciar una propuesta que corrobora su teología de la sola fe, a la vez que demuestra la capacidad de la misma para resolver un asunto que escapaba de la mera teología.

La confianza puesta por los contemporáneos de Lutero en aquellas profecías que, respaldadas por las reformas políticas de los emperadores del Sacro Imperio, promovían la realización de buenos actos (bien común) para evitar el castigo de Dios y alcanzar la salvación ${ }^{6}$, debió tener para él un gran desperfecto, la frialdad con la cual se concebía el Sacrificio del Cristo Redentor, cuya imitación nada tenía que ver, a su entender, con la verdad del Evangelio. La respuesta de Lutero a esta representación social del prodigio creemos que se encuentra fundamentada en el mismo argumento que venía desarrollando desde hacía algunos ańos como profesor de teología en la Universidad de Wittenberg, donde se habría conciliado con una interpretación literal de las palabras que Pablo había escrito a los Romanos y de acuerdo a las cuales, la redención de los pecadores "era asegurada por virtud de los acontecimientos narrados en los Evangelios, esas narraciones de la muerte y resurrección salvadoras de Cristo"7. Este mensaje era interpretado por Lutero como la negación del sentido tropológico de las obras y méritos de Jesús, según lo cual aquellas no requerían se imitadas ni proyectadas por los seres humanos en actos de amor y caridad, actos que durante el período temprano moderno podían verse reflejados

6 Maximiliano I reivindicó la propaganda imperial que había iniciado su padre, Federico III, la cual buscaba establecer el derecho divino de los Habsburgo por medio de estrategias de persuasión, tales como los pronósticos astrológicos. Uno de las necesidades más apremiantes que respaldaron el patrocinio imperial de este tipo de textos durante los siglos XV y XVI tenía que ver con la resolución del déficit presupuestario para enfrentar la amenaza turca. A propósito de lo anterior, Lichtenberger propiciaba el buen comportamiento de las autoridades (príncipes) de modo que Dios alejase de ellos su ira.

7 M. Mullet, Martín Lutero, Ediciones B Argentina, Buenos Aires 2009, 95. 
en las distintas formas de comportamientos que eran exigidas, ya no solo por los predicadores, sino por los mismos astrólogos de corte, quienes manipulaban el concepto de "acto benéfico" en términos de bien común. Por el contrario, para Lutero, el sentido tropológico era suplantado por la interpretación literal de la vida y muerte de Jesús, lo cual no era sino la forma interna a través de la cual el hombre por medio de su fe conquistaba el pecado, muerte e infierno, dando vida, justicia y salvación.

De esta doctrina de justificación por la sola fe habría de desprenderse la abolición del Cristo Legislador, aquel que hacía valer nuestros actos para el Juicio Final, de modo tal que los méritos del Hijo y la justicia que por su intermediación otorgaba su Padre se uniesen en una sola misericordia. Así, el hombre nada tenía que hacer para su Salvación, a excepción de recibir humildemente la gracia por medio de la sola fe. Eso permitía que el pecado pudiese permanecer sin necesidad de que ello impidiese la entrada del hombre a la vida eterna, pero, al mismo tiempo, significó que las acciones de caridad y bien común que les eran exigidas por la tradición cristiana tardomedieval, no tuviesen sentido alguno para el momento final.

Es sabido que la suma de la inextirpabilidad del pecado, más la ineficacia de los actos humanos, llevaron a Lutero a la conclusión más radical de todas, la inexistencia del albedrío humano. De aquello el monje habría de concluir en su célebre obra, el De Servo Arbitrio (1525), que el hombre pecador jamás podría realizar acciones provechosas de ningún tipo, de modo tal que cualquier acto salvífico surgía gracias a la misericordia divina y no por albedrío humano:

Pues una vez que se ha admitido y determinado que tras la pérdida de la libertad, el libre albedrío está bajo coacción en la servidumbre del pecado y no puede querer un ápice de lo bueno, yo puedo sacar de estas palabras esa única conclusión: que el libre albedrío es una palabra vacía cuyo contenido real se ha perdido ${ }^{8}$.

Cuando se refería a que el contenido real del término se había perdido, podríamos pensar que estaba haciendo alusión a un supuesto estado del ser humano previo al pecado original, o bien, a todos los años previos al

8 Postquam enim concessum ac ratum est, liberum arbitrium amissa libertate cogi in servitute peccati nec posse quicquam velle boni, ego ex his verbis nihil aliud possum concipere, quam liberum arbitrium eese inanem voculam, enius res amissa sit; $\mathrm{M}$. Lutero, "De Servo Arbitrio 1525” en Martin Luthers Werke, Kritische Gesamtausgabe, Hermann Böhlau, WA 18 1908, 18, 670, 33-36. 
nacimiento, vida, muerte y resurrección del Redentor, durante los cuales las personas aún no contaban con la gran oportunidad que inhabilitaría todos sus actos para alcanzar la Salvación.

Otro punto relevante en cual debemos reparar es que el pecado para Lutero no era un impedimento para que el hombre actuara libremente en su vida cotidiana, es decir, la ineficacia del albedrío humano se hacía evidente en relación al proceso salvífico, y no en todos los sentidos de la vida del hombre. Al respecto, el reformador logró dar un pequeño espacio en su De Servo Arbitrio a la libertad humana y cedió frente a sus oponentes:

Al hombre se le concede un libre albedrío no respecto de lo que es superior a él, sino sólo respecto de lo que es inferior. Esto es: el hombre debe saber que en lo referente a sus bienes y posesiones materiales, él tiene el derecho de usar, hacer y no hacer conforme a su libre albedrío, si bien también esto lo guía el libre albedrío del solo Dios en la dirección que a él le place; pero que frente a Dios, o en lo pertinente a la salvación o condenación, el hombre no posee un libre albedrío, sino que es un cautivo, un sometido y siervo ya sea de la voluntad de Dios, o la de Satanás?.

Si bien Dios actuaba por medio de los seres humanos, a éstos les pertenecía el derecho de usar, hacer y no hacer todo aquello que no tuviese que ver con Dios ni con el otorgamiento de Su gracia. Al menos en ese sentido, a las personas se les permitía sentir libertad y dominio sobre sus vidas. Para llevar este pensamiento al ámbito de las predicciones de la época debemos citar la definición que el monje agustino hizo de la profecía de Lichtenberger en el Prefacio de 1527: "Se trata de una profecía completamente material referente a cosas materiales y mundanas"10.

9 Quod si omnino vocem eam omittere nolnmus, quod esset tutissimum et religiosissimum, bona fide tamen eatenus uti doceamus, ut homini arbitrium liberum non respecto superioris, sed tantum inferiores se rei concedatur, hoc est, ut sciat sese in suis facultatibus et possessionibus habere ius utendi, faciendi, omittendi pro libero arbitrio, licet et idipsum regatur solius Dei libero arbitrio, quocunque illi placuerit. Caeterum erga Deum, vel in rebus, quae pertinent ad salutem vel damnationem, non habet liberum arbitrium, sed captivus, subiectus et servus est vel voluntatis Dei vel voluntatis Satanae. WA 18, p.638, 4-11.

10 Also das gar eine leibliche weissagung ist von eitel leiblichen dingen; M.Lutero, "Vorrede Martini Luthers auf die Weissagung des Johannis Lichtenbergers 1527", en Predigten und Schriften, Hermann BöHLau, WA23 1901, p.8, 14-15. 
De acuerdo a nuestra interpretación, se sostiene que, de haber sido una profecía material referente a cosas mundanas, cabría pensar que el pronóstico del astrólogo alemán era obra de su libertad, gracias a la cual él hacía lo que deseaba. De ser así, nos quedaría por preguntarnos ¿por qué Lutero la crítica? El problema estaba en que, indiferente de las técnicas de conocimiento que tuviese el astrólogo, lo cierto era que su proyección de conocimiento convergía con el principio de la omnisciencia, el cual solo podía ser una propiedad de la divinidad. Por eso es que Lutero restringe la libertad de los hombres cuando se trata del conocimiento de los tiempos venideros, de modo que una persona solo podía profetizar por intermediación del Espíritu Santo:

Hay algunos profetas que vaticinan exclusivamente a partir del Espíritu Santo [...] Como testifica también Pedro, 2 Pe 1. "la profecía de la Escritura nunca procede de interpretaciones propias, porque jamás ha habido una profecía que se deba a la voluntad humana, sino que los santos hombres de Dios han hablado impulsados por el Espíritu Santo» ${ }^{11}$.

Esta desavenencia lo dirigió a defender la naturaleza divina contra quienes creían que su raciocinio les permitiría comprenderla. En ese caso -y siguiendo el pensamiento del monje alemán- la acción de Lichtenberger no habría estado dirigida a algo mundano "inferior a él”, sino superior en todos los sentidos, en la medida que su escrutinio interfería directamente con la obra de Dios. En efecto, su objetivo debió ser comprendido por Lutero como una acción impía en cuanto creía tener el poder necesario para descifrar los prodigios divinos ${ }^{12}$. Desde ese punto de vista, la

11 Erstlich sind etliche Propheten, welche alleine aus dem heiligen geiste weissage [...] Wie auch Petrus zeuget 2 Bet.1:"Die weissagung der schrifft kommt nicht aus eigener auslegunge, denn es ist noche nie keine weissagung aus menschen willen erfurbracht, sondern die heiligen menschen Gottes haben geredt, getrieben vom heiligen geist,, wa 23, 7-12, 16,21. Para la presente investigación contamos también con la versión en castellano que se encuentra en el Apéndice de la obra citada de A. Warburg.

12 Lichtenberger había sostenido lo siguiente: Aunque el mismo Cristo testimonia la verdad eterna y sólo él conoce las cosas futuras [...] no por ello es menos cierto que el mismo Dios bondadoso, por su clemencia e infinita bondad y misericordia, ha concedido a sus criaturas diversos dones permitiéndoles comprender y conocer algunas cosas futuras aún lejanas/ Wie Christus die ewig warheit selbs (selbst) bezeugt. Er auch allein zukünfftige Ding merk [...] nichts desto weniger hat Derselbig gütige Gott auss seiner milten (Milde) überflüssigen güte (Güte) und barmherzigkeit mancherlen gaben in seine Creaturn gegossen. Damit er ihnen etlige Ding die noch ferne und zukünftig sind zuverstehen und zuwissen vergünner $(\dot{\xi})$ hat; J. Lichtenberger, Die Weissagung..., 1 . 
definición de lo "mundano" de Lutero se contradeciría con lo que, para él, hacía Lichtenberger al atentar contra los arcanos de Su Majestad.

En lo que respecta al proceso salvífico, la dicotomía que podía existir con la dependencia astral es nuestra mayor preocupación. De acuerdo a lo señalado por el reformador en su obra de 1525 , respecto a que "en lo pertinente a la salvación o condenación" el hombre no poseía albedrío alguno, podría sostenerse también que la profecía de Lichtenberger no debió tener nada de mundano para el monje alemán, sobre todo porque la predicción del vaticinador tenía que ver justamente con el llamado de reforma imperial y bien común para alcanzar la gracia ${ }^{13}$. Para profundizar en ello nos dirigiremos a otros argumentos de su Prólogo que han llamado nuestra atención.

Una de las razones debido a las cuales Lutero cuenta que escribió un nuevo prefacio para la reedición de la Pronosticatio, fue la siguiente:

Teniendo en cuenta también que de este libro ha surgido el rumor casi general de que se atacaría a los curas y después las cosas volverían a su cauce y éstos dicen ahora que ya ha sucedido y que han salido bien parados de ellos y que este Lichtenberger -autor de la profecía- se refiere a la persecución debida a la sublevación de los campesinos y a la doctrina de Lutero ${ }^{14}$.

La confianza que tenía el clero alemán en que, luego de la revuelta del campesinado, vendrían tiempos de paz para ellos, es uno de los motivos históricos que repercutió en la respuesta del reformador. No obstante, de acuerdo a nuestro análisis, la molestia habría surgido no solo del odio y divergencia de opinión sobre los asuntos doctrinales que venían sumándose

13 Lichtenberger promovía la figura de Maximiliano I como el baluarte en el cual los cristianos debían confiarse para iniciar una Reforma que pudiese poner fin a la amenaza de los turcos. En una de sus profecías, el astrólogo mostraba qué era lo que cada grupo social debía hacer, de modo que su palabra se convertía en la imposición de una ley que animaba a actuar de acuerdo al bien común, cuya realización podía darse de diversas maneras, ya sea por medio de la oración, la protección o el trabajo: "Al Papa: tú debes orar; al emperador: tú debes proteger; y a los campesinos: tú debes trabajar"/ Zum Papst/ Su sollst beten. Zum Kaiser /Du sollst beschirmen. Und zum Bauern/ du sollst arbeiten: Die Weissagung Johannis Lichtenbergers: Deutsch mit schönen Figuren zugericht (1557). J.Lichtenberger, Die Weissagung... , 20.

14 Nach dem aus diesem buch ein fast gemeine rede ist entstanden gewest: Es wurde ein mal über die (Pfassen) gehen und danach wide $r$ gut werde, und meinen, es ja an geschehen, sie jeden hindurch, das ihr verfolgung durch der bauren auffrur und des Luthers lere sen von jedem Lichtenberger gemeinet.WA 23, p.7, 7-11. 
al debate confesional, sino también de la percepción que los hombres de su época tenían de los Pronósticos. En relación a lo mismo, es necesario que nos refiramos a lo que dijo al final de su prefacio: "Si mis inclementes señores, los religiosos, se alegran como si ya hubieran superado todo y ahora hubiera de irles bien, les deseo suerte porque la van a necesitar" ${ }^{15}$.

Aquella frase muestra la discrepancia que existía entre la recepción que él había hecho de la obra de Lichtenberger y la realizada por sus enemigos teológicos; evidencia la molestia que sintió el reformador hacia la certidumbre que tenían sus contemporáneos sobre los anuncios futuros. Su crítica hacia la creencia astral también nos lleva a inferir que su preocupación tuvo que ver con las percepciones de su presente y no con un asunto personal con el astrólogo alemán, ya fallecido para ese entonces. Por último, el desacuerdo que sintió el monje agustino por la forma en la cual el clero había interpretado la obra en cuestión, nos corrobora que la atención dirigida al Pronóstico no tuvo mucho que ver con la percepción de algo material y mundano. Hay una forma de comprender el prodigio por parte de sus contemporáneos que a Lutero sin duda le pareció incorrecta y en relación a lo cual el concepto de libre albedrío -desde la perspectiva salvífica- fue clave. De allí que su objetivo entonces consistiera en enseñar a los lectores de su época cuál era la acogida que se debía hacer de las predicciones y para comprender ello, su concepción unilateral de la Justicia Divina nos resulta fundamental.

\section{LA VERDADERA LEY Y EL VALOR DE LA HUMILDAD}

Una de las consecuencias teológicas de la ausencia del Cristo Legislador era la inmediata abolición de la Ira Divina, representada como aquel ultimátum que llamaba a hacer el bien para alcanzar la gracia, una Ira de la cual se desprendían acciones relacionadas con el Bien Común, el Amor y la Caridad, y que para Lutero no se correspondían con una lectura correcta de las Sagradas Escrituras. Este quiebre bien pudo ser una falta al credo católico, pero también puede concebirse como una solución al miedo y amor surgido del Evangelio de la Ley.

15 Das nu meine ungnebige herrn, die geistlichen, sich freuen, als sehen sie hinüber und solle ihn nu hinfurt wol gehen, da wünsch ich ihn glück su, sie (dürffens) wol. WA 23, p. $12,5-7$. 
Cuando hablamos de que existió un desprecio hacia la ley en la doctrina del reformador, no debemos suponer que aquel haya pensado en omitir aquel término de su enseñanza, sino muy por el contrario, pudo integrarlo en su doctrina gracias a la teología paulina. En su intento por responder a una de las preguntas que se había hecho Erasmo de Rotterdam respecto a la relación que podía existir entre la ineficacia del libre albedrío y la ley, Lutero recurrió al discípulo y dijo lo siguiente:

Y con esto se resuelve aquella cuestión presentada por la Disquisición y repetida tantas veces en todo el trabajo: „Si no somos capaces de nada, ¿a qué vienen tantas leyes y preceptos, tantas amenazas y promesas?". Aquí Pablo da la contestación: „Por la ley es que se conoce el pecado“. Su respuesta a esta cuestión es muy distinta de lo que el hombre o el libre albedrío se imaginan. No existe en la ley prueba alguna para el libre albedrío, dice, ni tampoco coopera el libre albedrío en el logro de la justicia; pues lo que viene por la ley no es la justicia, sino el conocimiento del pecado ${ }^{16}$.

De acuerdo a la tradición católica a la cual pertenecía Erasmo y los nominalistas, la amenaza y promesa divina dependían de la relación que había entre el Juicio Divino y una libertad humana responsable del cumplimiento de la ley. Pero si no éramos capaces de hacer nada, entonces la ley inmediatamente carecía de sentido, puesto que su llamado estaba dirigido a un ser humano que no contaba con libertad de acción. Para el reformador alemán ello no suponía un problema, en la medida que el apóstol le había permitido comprender que la ley no sugería que hubiese ninguna advertencia ni amenaza por parte de Dios, sino solamente un medio para conocer la verdadera causa de la servidumbre humana, el pecado. La condición libre del hombre era reemplazada unilateralmente por su condición pecadora, de acuerdo a lo cual el albedrío humano nada tenía que ver con la justicia, puesto que esta última hacía referencia exclusiva a la conciencia sobre el pecado y no al seguimiento de ley alguna. Unas hojas más abajo, Lutero se refirió a la separación que había realizado San Pablo entre la justicia y la ley:

16 Atque hic solvitur illa quaestio Diatribes, totíes toto libello repetita: Si nihil possumus, quid faciunt tot leges, tot praecepta, tot minae, tot promisiones? Respondet hic Paulus: per legem cognitio peccati. Longe aliter respondet ad eam quaestionem, quam homo aut liberum arbitrium cogitat. Non (ait) probatur liberum arbitrium per legem, Non cooperator ad iustitiam, Non enim per legem iustitia, ed cognition peccati. WA 18, p.766, 19-25. 
Pablo dice que la justicia que vale ante Dios se manifiesta sin la ley, distinguiendo así la justicia que vale ante Dios de la justicia proveniente del cumplimiento de la ley. Pues la justicia de la fe resulta de la gracia, sin [que en ello intervenga] la ley. Las palabras de Pablo: „sin la ley" pueden tener sola y únicamente el significado de que la justicia cristiana existe sin las obras de la ley, esto es, que en la obtención de esta justicia, las obras de la ley no cuentan para nada ni como aporte ni como medio ${ }^{17}$.

La justicia proveniente del cumplimiento de la ley era aquella justicia que evaluaba y calificaba, y que por lo tanto, no tenía validez frente a Dios, al contrario de la justicia procedente de la gracia para la cual no eran necesarios los cumplidos, sino solo la fe. De acuerdo a ello, podemos ver que las obras de la ley eran para Lutero lo mismo que se dijese "hacer justicia sin la ley" ya que la inexistencia del albedrío humano significaba que las obras no se requerían y, por ende, la ley no tenía razón de ser frente a una justicia independiente que obraba por medio de la sola fe. Esta es una forma de explicar la ventaja que ganaba en su pensamiento el sacrificio del Cristo Redentor por sobre el Cristo Legislador, puesto que, mientras al primero convenía la abolición del albedrío humano, de modo tal que su causa redentora fuese entendida como la única causa de la justificación, el segundo se veía perjudicado porque su ley no tenía respuesta por parte de la condición pecadora de las personas a las cuales estaba dirigida.

En efecto, el pecado era inherente al hombre, porque al fin y al cabo, la única forma de que los actos de Cristo adquiriesen sentido y fuesen causa única de Salvación, era permaneciendo en el error. De allí que la ira de Dios no podía comprenderse como una respuesta a los actos del piadoso e incluso, tampoco podía entenderse como un castigo al hombre, ya que eso habría significado ir contra el sentido y naturaleza de su divinidad. Por ende, cuando Lichtenberger señalaba que la fe era necesaria para que Dios perdonara nuestras faltas, de modo tal que el castigo que se anunciara por

17 Iustitia Dei sine lege (inquit) manifestatur. Secernit iustitiam Dei a legis iustitia. Quia iustitia fidei venit ex gratia sine lege. Hoc quod dicit: Sine lege, aliud nihil esse potest, quam quod iustitia Christiana constet sine operibus legis, sic quod opera legis nihil pro ea valeant aut facient obtinenda. WA 18, p.767, 26-30. 
medio de los cielos pudiese evitarse, o bien, resistirse de buena manera ${ }^{18}$, aquel estaba pensando en la justificación por una fe que actuaba como respuesta a la ley y no como una fe que actuaba de acuerdo al agradecimiento, ni mucho menos estaba considerando la connotación pecadora permanente de los seres humanos. La fe no era solo un don recibido, sino algo así como un transporte cuyo avance hacia la Salvación dependía del impulso otorgado por la conciencia caritativa y la obediencia al Cristo Legislador. En el caso del Pronóstico de 1488, la fe adquirió el rol del bien común a través del cual la ley seguía imperando sobre las acciones de las personas.

Este breve cuadro comparativo es fundamental para comprender cómo, para Lutero, el prodigio no podría ser concebido desde el punto de vista de una advertencia, puesto que la esencia del hombre estaba corrompida por causa de la inevitabilidad del pecado, cuya consecuencia tenía que ver con la recepción humilde del presagio más que con una respuesta a él. En el De Servo Arbitrio su autor ya había dejado establecido lo siguiente:

Dios por cierto prometió su gracia a los humildes [...] el que no duda por un momento de que todo está en la voluntad de Dios, no elige nada, sino que espera que Dios obre; siendo más cercano a la gracia, de modo que puede ser salvado ${ }^{19}$.

Llevando esta idea al terreno de los Pronósticos Astrológicos, aquel que se confiaba en el vaticinio como un llamado a hacer algo, aquel que

18 Por esto mismo, que se protejan y prevengan cuanto puedan y que no den crédito a cualquier espíritu, pues la fe y la fidelidad son en este momento una rara avis en el mundo. Pero si no existen la fe y la confianza no puede haber ningún buen consejo, y si no se encuentra consejo alguno en la tierra, no existe ningún otro refugio salvo buscar auxilio, consejo y apoyo en Dios, en el Altísimo. J. Lichtenberger, Die Weissagung (WARBURG), 502.

19 Deus certo promisit humiliatis, id est, deploratis et desperatis, gratiam suam [...] Qui vero nihil dubitat, totum in voluntate Dei penderé, is prorsus de se desperat, nihil eligit, sed expectat operantem Deum, is proximus est gratiae, ut salvus fiat, WA $18,632,29-36,633,1$. 
sentía que Dios le estaba advirtiendo sobre un evento futuro, era aquel que estaba convencido de que su respuesta era indispensable en la medida que le permitiría no desesperar del todo, ya que sabía que de él dependía la realización de los cambios necesarios requeridos para asegurar su $R e$ dención. En una época como la de Lutero, en la cual el fervor religioso, la incertidumbre respecto a la absolución de los pecados y la piedad acercaban al hombre a su perdición y humillación, se alzaba esta esperanza por medio de la cual el ciudadano piadoso confiaba en que sus acciones eran anheladas desde lo Alto. Esta falta de humildad era para el monje alemán el obstáculo que impedía ser salvado, a diferencia de la recepción pasiva, la cual se condecía con su idea de la sola fe gracias a la cual el cristiano de nada debía preocuparse, sino solo humillarse ante Dios. Desde ese punto de vista, la desesperación de no hacer nada no sería castigada sino recompensada una vez que el cristiano fuese consciente de su dependencia absoluta del Cristo Redentor.

Esta postura sobre la humildad cristiana es la que nos ha sido posible encontrar en el Prólogo de 1527. En lo que respecta a los argumentos en los cuales Lutero dio su opinión sobre la representación de los eventos celestes, allí es posible ver que, en su preocupación por calmar la ansiedad de sus contemporáneos, dio a conocer uno de sus fundamentos teológicos más importantes, y que constituyó -el menos en teoría- un requisito esencial para hacer frente al prodigio.

\section{SoluCión AL PRODIgio: ABOLICIÓN DEL CASTIGo CELESTE Y LIBERACIÓN DE}

\section{LA CONCIENCIA PECADORA}

El monje acudió a la recepción humilde de sus contemporáneos, no con el fin inmediato de humillarlos, sino más bien con el fin, no sabemos si explícito, de exponer aquella posibilidad a través de la cual el cristiano entendiese cuál era su verdadero rol para la Salvación:

Junto a los ángeles, también dispone Dios sus señales cuando va a ocurrir una desgracia y hace aparecer cometas o priva a la Luna y al Sol de su luz o hace que aparezca una figura desacostumbrada [...] Con semejantes señales amenaza a los impíos y anuncia un accidente futuro que caerá sobre los señores y los países para de este modo advertirlos. Nunca ocurre nada semejante debido a los piadosos pues no lo 
necesitan: por ello, también se les dice que no deben temer las señales del cielo, como dice Jeremías, pues no les concierne a ellos, sino a los impíos $^{20}$.

Este párrafo consideramos que contiene lo necesario para conocer la doctrina luterana desde una perspectiva más positiva. Primero que todo, Lutero distinguió entre el impío y el piadoso. El reformador no necesitaba que la fe actuase para remediar la ira de Dios, sino más bien para tranquilizar a aquellos que ya se habían humillado frente a su misericordia. Aquel piadoso era justamente quien estaba consciente de la unilateralidad de la Justicia Divina, y por ende, sabía que la misericordia de Dios y la Redención de su hijo se habían unido en su favor a pesar de su condición pecadora. El piadoso sabía que Dios no debía perdonarle nada y que por ende, no existía ninguna posibilidad de que los anuncios proféticos fuesen dirigidos en su contra. Como había dejado escrito dos años antes, Cristo ya había hecho todo por nosotros:

Por la venida de Cristo al mundo a través del Evangelio, por el cual la gracia es ofrecida y ninguna obra exigida, se les ofrece a todos los hombres la oportunidad, verdaderamente una oportunidad gloriosa, de volverse hijos de Dios si están dispuestos a creer $^{21}$.

La oportunidad que, según Lichtenberger, Dios había otorgado al hombre para conocer el futuro mediante el don de la sabiduría y de la revelación $^{22}$, era reemplazada en el pensamiento de Lutero por la oportunidad de recibir la gracia por la sola fe. Por lo demás, aquella posibilidad de conocer el futuro se relacionaría con un poder que igualaría al ser humano con Dios, lo cual era completamente imposible para él. En efecto, la justi-

20 Über das tut Gott am himel auch seine zeichen, wenn sie ein unglaud treffen sol, und lest schwanzsterne entsethen oder Sonn und Mond schein verlieren oder sonst ein ungewöhnliche gestalt erscheinen [...] Mit solchen zeichen (bedroht) er den gottlosen und zeigt an zukunfftig unfal uber herrn und lande, sie zu warnen. ...der fromen willen geschicht solchs nichts, denn sie durffens nicht, darum wird ihn auch gesagt, Sie sollen sich des himels zeichen nicht furchten, asl Jeremias spricht, denn es gilt ihn nicht, sondern den gottlosen, WA 23, 10, 6-15.

21 Veniete Christo in mundum per Evangelion, quo offertur gratia, non autem exigitur opus, copiam fieri cuncits hominibus, magnificam sane, ut filii Dei siut, si credere velint, WA 18, 698, 1-3.

22 El mismo Dios bondadoso, por su clemencia e infinita bondad y misericordia, ha concedido a sus criaturas diversos dones permitiéndoles comprender y conocer algunas cosas futuras aún lejanas. J. Lichtenberger, Die Weissagung... (WARBURG), 500-501 
ficación por medio de la fe en la Redención abolía automáticamente cualquier efecto catastrófico que se creyera que pudiese tener la conjunción Júpiter-Saturno en la cual había basado el astrólogo su obra. Una vez que el hombre estuviese dispuesto a creer en el Cristo Redentor, se convertiría en aquel piadoso que obtendría la solución frente a la advertencia divina. Aquel recurso, por lo tanto, no era el bien común, ni la caridad, sino el reconocimiento de la misericordia como aquel obsequio que permitía al hombre confiar en su salvación. Asimismo, el prodigio no llamaría a actuar sino a aceptar la condición pecadora de la esencia humana.

El mensaje del reformador adquiría así un sentido esperanzador completamente distinto al anunciado por el astrólogo. Al fin y al cabo, su concepción unilateral de la Justicia Divina era la solución frente al temor y respeto que se tenía del Juicio Divino, y que venía amedrentando a la sociedad alemana desde hacía décadas. La esclavitud de la conciencia pecadora por medio de la cual el hombre sentía agonía y miedo frente a Dios, era reemplazada así por la esclavitud de la libertad humana que paradójicamente liberaba al hombre de toda ansiedad anunciada por las profecías apocalípticas y catastróficas.

Resulta interesante que, de su interés por convencer a los religiosos de su época de que su impiedad traería consigo el cumplimiento de la amenaza, surgiera una exposición de su doctrina de la sola fe. Ya dijimos que la única autoridad profética para Lutero derivaba de algunos pasajes bíblicos (citaba los ejemplos de Pedro, 2 Pe 1 y Zacarías, 7.), respecto de lo cual más abajo decía: "esta profecía tiene como tema y fundamento el hecho de que los impíos serán condenados y los piadosos redimidos y su objetivo es siempre afianzar y alentar las conciencias y la fe en Dios"23.

Enseguida señalaba que la profecía afectaba a los impíos solo "en cuanto que los amenaza y los condena" ${ }^{24}$. Si nos guiamos por su pensamiento teológico, podría inferirse que aquel que no valoraba al Cristo Redentor estaba desprotegido de la Misericordia Divina de modo tal que la profecía si estaba dirigida al infiel. Sin embargo, Lutero se encargó de aclarar que los vaticinios del astrólogo no tenían nada que ver con la mano de Dios. De

23 Dieser Weissagung ist gericht und geht darauf, das die gottlosen gestrafft, die fromen erlöst werden, und treibt immer darauf den glauben an Gott und die gewissen zu sichern und auszurichten, WA 23, 7, 21-24.

24 Denn das sie ihn bedrohet und sie straffet, WA 23, 7, 26. 
acuerdo a ello, pensamos que su intención por contradecir el pensamiento de sus religiosos, situándolos a ellos entre aquellos impíos que serían condenados por las figuras y sucesos descritos en la Pronosticatio, es una más entre tantas de sus ironías que se mezclaron usualmente en sus escritos más polémicos, sobre todo en aquellos en los que refutaba a quienes habían convertido a su figura en objeto de burla y discusión. En efecto, el vaticinio no podía ser una amenaza para el religioso puesto que aquel no venía de Dios. Para hacer frente a sus enemigos teológicos entonces, reconoció de una forma forzada, o humorísticamente, que los vaticinios de Lichtenberger se cumplirían para aquellos que se habían equivocado al creer que los anuncios de 1488 podían ser provechosos para su época, puesto que aún no habían logrado comprender la verdad de las Sagradas Escrituras. En ello consistía otra de las conclusiones del prólogo:

La summa summarum de todo lo dicho es que los cristianos no deben consultar semejantes prodigios, pues ellos se han encomendado a Dios y no necesitan amenazas ni advertencias de este tipo. Pero como Lichtenberger anuncia señales del cielo, los señores y los países impíos deben temer semejantes profecías y no pensar sino que les concierne a ellos ${ }^{25}$.

La amonestación no era necesaria para aquel que se había encomendado a Dios, de modo tal que el pronóstico astrológico no haría nada malo a aquellos humildes, fieles receptores del Cristo Redentor. Es importante que hagamos notar que, a pesar de que la profecía del astrólogo alemán no haya tenido nada de cierta para Lutero, aun así él acudió a su teología para calmar a los piadosos. Para enseñar a aquellos impíos que aún no se habían convertido al luteranismo y que, por tanto, creían en la Misericordia Divina como una justificación de los actos, el monje agustino se alejó de sus principios, recurrió a la ironía y al desprecio. Si la profecía de Lichtenberger era a sus ojos algo mundano e incierto y si los verdaderos profetas se reducían únicamente a aquellos anunciados por Dios, entonces su llamado a que "los impíos debiesen temer" debía ser una estrategia por medio de la cual buscaba oponerse a los religiosos de su época y no una

25 Und ist das Summa Summarum davon: Christen sollen nichts nach solcher weissagunge fragen, denn sie haben sich Gott ergeben, durffen solchs warnen nicht. Weil aber der Lichtenberger die zeichen des himels anzeucht, sol sollen sich die gottlosen herren und lender für allen solchen weissagungen furchten und nicht anders benden denn es gelte ihn, WA 23, 11, 16-20. 
exposición de su doctrina, como sí lo fue para el ámbito en el que se refirió a los piadosos.

Para estos últimos no acudió a la ironía sino a su pensamiento más radical. La solución frente al presagio estaba dentro de sí mismos, se hallaba en las páginas del Evangelio, en las que Lutero advirtió cómo la vida de Jesús no era un llamado a imitar sus acciones, sino a comprender, a ser consciente de que la justificación redentora por medio de la fe era la única forma de ser salvados. En efecto, la exhortación que hacía creer al individuo que la ira se desataría por su indiferencia hacia los prodigios vendría a ser, de acuerdo al pensamiento del monje alemán, absoluta ignorancia e indiferencia en lo referente al valor de los méritos de Jesús. Lo que hacía el astrólogo era manipular al Cristo Legislador, utilizar la ira divina de acuerdo a un procedimiento salvífico que no tenía mucha relación con $\mathrm{Su}$ justicia.

Como dijimos, la humildad y agradecimiento a Dios era reemplazado por el temor y el miedo. Esta actitud debió ser una de las raíces del completo rechazo de Lutero a una comprensión de la Biblia como ley y su rotunda oposición al presagio como un signo positivo o negativo. La relación con el pronóstico no debía ser análoga a los pecados que se hubiesen cometido, puesto que ello solo hacía que el hombre se confiara en una ley errónea y malinterpretada, y de acuerdo a la cual el terror hacia la Providencia estaba disfrazado por una amor, una caridad y un bien común forzado por la esperanza en la consolación, antes que en el Espíritu Santo. En su De Servo Arbitrio, el monje alemán había planteado su incomodidad frente a la enseñanza de la ley predicada por el Pontificado y el mismo Erasmo:

¿Y a esto llamas enseñar teología? ¿Al ligar con leyes a las almas y (como dice Ezequiel) matarlas, almas que Dios no ligó? Indudablemente, con una argumentación así alzas contra nosotros toda la tiranía de las leyes papales como si fuesen útiles y de provecho para la salvación ${ }^{26}$.

Conteniendo su disgusto respecto a la amonestación, Lutero proponía cómo debía enseñarse correctamente al cristiano:

26 Hoccine est Theologiam docere? Animas ligare legibus et (ut Ezechiel dicit) mortificare, quae ligatae non sunt a Deo? Scilicet hac ratione nobis suscitas universam tyrannidem Pontificarum legum, tanquam utilem et salutarem, WA 18, p.624, 8-11. 
Un teólogo bueno enseña así: Si el pueblo hace lo malo, debe ser contenido por la fuerza exterior de la espada, como enseña Pablo en Romanos 13; pero no debe atraparse la conciencia de la gente con falsas leyes para que se vean atormentados por pecados allí donde Dios quiso que no hubiera pecados ${ }^{27}$.

Dejando a un lado su teoría del poder secular, es de gran significado que Pablo siguiese apareciendo en aquellos argumentos en los cuales el temor a Dios por medio de la ley buscaba ser disipado. Ya desmenuzado nuestro argumento, podemos ver la preocupación permanente del reformador alemán por la conciencia de sus contemporáneos, su desdén hacia los argumentos que inducían a seguir confiando en la remisión de los pecados, cuando él estaba completamente convencido de que Dios jamás actuaría en relación a ellos.

Al mismo tiempo, un tema muy recurrente en su obra teológica tenía relación con una frase de Ezequiel (18: 23), quien había hablado en nombre de Dios de la siguiente manera: „No quiero la muerte del pecador, sino antes bien que se vuelva y viva“. La alusión que hacía el monje alemán de esta frase tenía que ver con su necesidad de demostrar la bondad y promesa divina como un cumplimiento a través del cual la justicia actuaba inmediatamente, sin juzgar los actos del pecador. Una de aquellas promesas tenía que ver con que Dios decía ser misericordioso, lo cual para el reformador se entendía como un "no quiero castigar, no quiero que vosotros muráis, quiero perdonar, quiero ser indulgente" 28 . Lutero reconocía que Erasmo se había equivocado al interpretar dicha afirmación, puesto que había omitido distinguir entre las palabras de la ley y palabras de promesa:

A este pasaje de Ezequiel le da un carácter legalista y lo explica así: "no quiero la muerte del pecador", estos es; "no quiero que cometa un pecado mortal o que llegue a ser un pecador digno de muerte, sino antes bien, que se vuelva del pecado si es que cometió uno y así viva ${ }^{29}$.

27 Bonus Theologus sic docet: Vulgus coercendum est externa vi gladii, ubi male egerit, sicut Paulus docet Roma. 13. non autem conscientiae eorum falsibus legibus irretiendae sunt, ut peccatis divexentur, ubi peccata non esse Deus voluit. WA 18, p.624, 12-15.

28 Nolo punire, nolo vos mori, volo ignoscere, volo parcere. WA 18, p.683, 21-22.

29 Sed Diatribe nostra iterum nihil inter legis et promissionis verba distinguens facit hunc locum Ezechielis vocem legis ac sic exponit: Nolo morten peccatoris, id est, nolo, quod mortaliter peccet aut fiat peceator mortis reus, sed magis ut convertatur a peccato, si quod fecerit, et sic vivat. WA 23, p.683, 28-31. 
El ignorante que hacía esta afirmación -según el monje- pensaba que el profeta había aludido a que Dios no quería el pecado del hombre, pero lo cierto era que el único castigo que podía haber era la aflicción que la persona sentía por su condición errante. De acuerdo a esto, el temor que los contemporáneos del reformador sentían por las consecuencias que sus pecados pudiesen tener en caso de que no actuaran por medio de la ley y, por ende, no tomasen conciencia sobre los males que anunciaba Dios desde los cielos, conllevaba a la misma incorrección. Si Dios pensaba en los seres que había creado como seres a los cuales debía su gracia porque éstos no contaban con el albedrío necesario para alcanzarla, entonces el castigo era reemplazado por un deber inherente a la naturaleza divina, aquella justicia en esencia propia de su condición, gracias a la cual Aquel estaba obligado a justificarnos si teníamos fe.

La unilateralidad de la Justicia Divina de Lutero se dirigió, al menos en teoría, al rescate de la conciencia pecadora del siglo XVI, al mismo tiempo que se convirtió en una alternativa salvífica de lo más relevante frente a la esperanza funesta en los actos humanos que el astrólogo buscaba insertar en la mente de sus lectores. El pensamiento del reformador alemán se alzaba como una solución unilateral a la amenaza del vaticinio en la sociedad alemana, un escape a la representación bi-funcional del Juicio Divino que actuaba por medio del texto bíblico y de los prodigios celestes.

\section{Conclusión}

Un estudio del pensamiento teológico del reformador alemán llevado al terreno de la Astrología nos ha permitido analizar su doctrina bajo una perspectiva que no ha sido del todo considerada a nivel historiográfico. A partir de la revisión del Prólogo a la Astrología, y en compañía de algunos principios teológicos que aparecen en el De Servo Arbitrio, nos fue posible evidenciar un mensaje instructivo que buscaba revertir la confianza que sus contemporáneos habían depositado en las profecías astrológicas.

Ello correspondía a una malinterpretación del sentido salvífico del Evangelio, cuyo verdadero significado para Lutero era similar al de los prodigios celestes, en la medida que el buen cristiano debía comprenderlos fielmente como aquella parte clara y visible de un Dios piadoso que nos había hecho justicia a través de un Cristo Redentor, cubriendo nuestros pecados con sus actos, abriéndonos así el camino hacia la Salvación. De 
esta manera, la creencia en la influencias astral como un llamado a actuar en favor del bien común y salvación se entendía como una indiferencia hacia la redención de Cristo, en favor de una ley punitiva a la cual Lutero habría renunciado mucho tiempo atrás. La clave estaba en insistir en la esclavitud e ineficacia de la voluntad humana como la única forma que haría al hombre libre de su conciencia pecadora. 